\title{
Asia-Pacific Colorectal Screening Score Should Be Considered as an Adjunctive Tool to Identify Asian Patients With Irritable Bowel Syndrome Symptoms Who Have Priority for Colonoscopy
}

TO THE EDITOR: We read the "Second Asian consensus on irritable bowel syndrome" by Gwee et al ${ }^{1}$ with interest. We would like to emphasize on the importance of correct diagnosis of the disorder. Generally, the diagnosis of irritable bowel syndrome (IBS) could be established based on clinical grounds if patients fulfill clinical criteria and have no alarm features. ${ }^{2,3}$ However, there are emerging evidences that colorectal cancer (CRC) may mimic IBS, and alarm features have unacceptably low sensitivity for CRC.

First, a Danish cohort study on 57851 IBS patients reported $522(0.9 \%)$ patients with CRC. ${ }^{4}$ In this study, there was a significantly increased risk of CRC in the first 3 months after an IBS diagnosis. Our study on 404 Vietnamese patients with IBS symptoms fulfilling the Rome III criteria found $2.2 \%$ of patients with CRC, ${ }^{5}$ and $\mathrm{CRC}$ was significantly associated with a short onset ( $\leq 2$ years) of symptoms, but not with alarm features.

Second, alarm features are reported to have very low sensitivity for CRC in patients with lower gastrointestinal symptoms worldwide. A meta-analysis on 19443 patients, mainly from Europe and United States of America, found that the sensitivity ranged from 5.0-64.0\%. ${ }^{6}$ Similarly, a recent colonoscopy database review on 10 603 patients in China reported that the sensitivity was only $9.6 \%$.

Adjunctive tool, therefore, is crucial for daily practice. The Asia-Pacific Colorectal Screening (APCS) score is firstly developed to stratify risk for $\mathrm{CRC}$ in asymptomatic Asian subjects (Table). ${ }^{8}$ Our recent study ${ }^{6}$ found that it could be applied for patients with IBS symptoms. All of CRC patients with IBS symptoms who presented with no alarm features had high APCS scores. Besides, there were $4.7 \%$ of IBS patients with advanced colorectal adenomas. Compared to patients with an APCS score of 0 to 1 , those with a score of 2 to 3 and 4 to 7 had 5.6-fold and 12.1-fold increase in odd for $\mathrm{CRC}$ or advanced colorectal adenomas, respectively. The APCS score, therefore, could be used to identify IBS patients with priority
Table. The Asia Pacific Colorectal Screening Score

\begin{tabular}{|c|c|c|}
\hline Risk factor & Criteria & Points \\
\hline \multirow[t]{3}{*}{ Age (yr) } & $<50$ & 0 \\
\hline & $50-69$ & 2 \\
\hline & $\geq 70$ & 3 \\
\hline \multirow[t]{2}{*}{ Gender } & Female & 0 \\
\hline & Male & 1 \\
\hline \multirow{2}{*}{$\begin{array}{l}\text { Family history of colorectal cancer in } \\
\text { a first degree relative }\end{array}$} & Absent & 0 \\
\hline & Present & 2 \\
\hline \multirow[t]{2}{*}{ Smoking } & Never & 0 \\
\hline & Current or past & 1 \\
\hline
\end{tabular}

A score of 0-1defines average risk, 2-3 moderate risk, and 4-7 high risk.

for colonoscopy. In the management of IBS, reassurance on the benign progression of the disease is important. ${ }^{1-3}$ But follow-up during the first 1 year to 2 years after IBS diagnosis should be considered for any change in symptoms, especially for patients with high APCS score who not yet undergo colonoscopy. Asking patients with IBS symptoms to revisit when alarm features develop may be too late.

Duc T Quach ${ }^{1,2 *}$ and Toru Hiyama ${ }^{3}$ ${ }^{1}$ Department of Internal Medicine, University of Medicine and Pharmacy, Hochiminh, Vietnam; ${ }^{2}$ Department of Gastroenterology, Gia-Dinh People's Hospital, Hochiminh, Vietnam; and ${ }^{3} H e a l t h$ Service Center, Hiroshima University, Higashihiroshima, Japan

1. Gwee KA, Gonlachanvit S, Ghoshal UC, et al. Second Asian consensus on irritable bowel dyndrome. J Neurogastroenterol Motil 2019;25:343362 .

2. Lacy BE, Mearin F, Chang L, et al. Bowel disorders. Gastroenterology 2016;150:1393-1407, e5.

3. Quigley EM, Fried M, Gwee KA, et al. World Gastroenterology Organisation Global Guidelines Irritable Bowel Syndrome: a global perspective update September 2015. J Clin Gastroenterol 2016;50:704-713.

4. Nørgaard M, Farkas DK, Pedersen L, et al. Irritable bowel syndrome 
and risk of colorectal cancer: a Danish nationwide cohort study. Br J Cancer 2011;104:1202-1206.

5. Quach DT, Hiyama T, Nguyen TA, Ly HQ, Tanaka S. Asia-Pacific Colorectal Screening score: a useful tool to stratify risk for colorectal advanced neoplasms in Vietnamese patients with irritable bowel syndrome. J Gastroenterol Hepatol 2018;33:150-155.

6. Ford AC, Veldhuyzen van Zanten SJ, Rodgers CC, Talley NJ, Vakil NB, Moayyedi P. Diagnostic utility of alarm features for colorectal cancer: systematic review and meta-analysis. Gut 2008;57:1545-1553.

7. Bai Y, Xu C, Zou DW, Gao J, Li ZS. Diagnostic accuracy of features predicting lower gastrointestinal malignancy: a colonoscopy database re- view of 10,603 Chinese patients. Colorectal Dis 2011;13:658-662.

8. Yeoh KG, Ho KY, Chiu HM, et al. The Asia-Pacific Colorectal Screening score: a validated tool that stratifies risk for colorectal advanced neoplasia in asymptomatic Asian subjects. Gut 2011;60:1236-1241.

\section{Financial support: None.}

Conflicts of interest: None.

Author contributions: Duc T Quach initiated the study conception, wrote the draft, and submitted the study; and Duc T Quach and Toru Hiyama critically revised the manuscript. All authors approved the final version of the draft. 